\title{
Angiographic outcomes of right internal thoracic artery grafts in situ or as free grafts in coronary artery bypass grafting
}

\author{
Toshihiro Fukui, MD, PhD, ${ }^{\mathrm{a}}$ Minoru Tabata, MD, MPH, ${ }^{\mathrm{a}}$ Susumu Manabe, $\mathrm{MD}, \mathrm{PhD},{ }^{\mathrm{a}}$ \\ Tomoki Shimokawa, MD, PhD, ${ }^{\mathrm{a}}$ Satoshi Morita, $\mathrm{MD}, \mathrm{PhD},{ }^{\mathrm{b}}$ and Shuichiro Takanashi, $\mathrm{MD}^{\mathrm{a}}$
}

Objective: We sought to compare early and 1-year angiographic results of various coronary artery bypass grafting configurations with the right internal thoracic artery in combination with the left internal thoracic artery.

\begin{abstract}
Methods: We reviewed the records of 705 patients who underwent bilateral internal thoracic artery grafting between September 2004 and November 2008. The right internal thoracic artery was used as an in situ graft in 547 patients and as a free graft in 158 patients. We compared operative and postoperative variables and early and 1 -year angiographic patency rates of the right internal thoracic artery between the groups.
\end{abstract}

Results: The operative mortality and incidence of postoperative complications were not significantly different between groups. The overall patency rates of the right internal thoracic artery were $98.8 \%$ at early angiography and $94.3 \%$ at 1 -year postoperative follow-up. There were no significant differences in patency rate between in situ and free right internal thoracic artery grafts $(98.6 \%$ vs $99.3 \%$ early and $95.3 \%$ vs $89.8 \%$ at 1 year). The best patency rate of the right internal thoracic artery was achieved with in situ grafting to the left anterior descending system $(99.4 \%$ early and $98.5 \%$ at 1 year).

Conclusions: Patency rates of in situ and free right internal thoracic artery grafts were similar in early and 1-year angiographic studies. Among various configurations, the best patency of the right internal thoracic artery was obtained with in situ grafting to the left anterior descending coronary artery. ( $\mathrm{J}$ Thorac Cardiovasc Surg 2010;139:868-73)

Internal thoracic artery (ITA) grafts are the most reliable conduits for revascularization of diseased coronary arteries because of their long-term durability. ${ }^{1}$ The use of bilateral ITA grafts has been shown to provide better survival and economic benefits than the use of single ITA grafts. ${ }^{2}$ Furthermore, the patency rate and survival benefits were satisfactory when bilateral ITAs were used for the left coronary system. ${ }^{3}$ There are, however, many different arrangements of the bilateral ITA in left-sided myocardial revascularization. In particular, the right ITA has been flexibly used as an in situ or free graft in combination with an in situ left ITA. ${ }^{4} \mathrm{An}$ in situ right ITA can be used for anterior territory (the left anterior descending coronary artery [LAD] and diagonal branch) along the front of the ascending aorta or lateral territory (obtuse marginal or posterolateral branch) through the transverse sinus. A free right ITA can be used as a composite graft or aortocoronary bypass graft. ${ }^{5}$

There is little information available on angiographic studies comparing these various configurations with bilateral

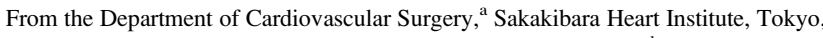
Japan, and the Department of Biostatistics and Epidemiology, ${ }^{\mathrm{b}}$ Yokohama City University Medical Center, Yokohama, Japan.

Disclosures: None.

Received for publication March 9, 2009; revisions received May 1, 2009; accepted for publication May 31, 2009; available ahead of print July 27, 2009.

Address for reprints: Toshihiro Fukui, MD, Department of Cardiovascular Surgery,

Sakakibara Heart Institute, 3-16-1 Asahi-cho, Fuchu City, Tokyo 183-0003, Japan

(E-mail: tfukui-cvs@umin.ac.jp).

$0022-5223 / \$ 36.00$

Copyright (c) 2010 by The American Association for Thoracic Surgery doi: 10.1016/j.jtcvs.2009.05.033
}

ITA grafting. The aim of this study was to examine the early and 1-year angiographic results of various strategies with right ITA grafts in combination with in situ left ITA grafts. Furthermore, we sought to evaluate the serial angiographic outcomes of right ITA grafts.

\section{MATERIALS AND METHODS Patient Population}

Between September 2004 and November 2008, a total of 827 patients underwent isolated coronary artery bypass grafting at Sakakibara Heart Institute. Of these patients, $705(85.2 \%)$ underwent bilateral ITA grafting. Preoperative characteristics of these 705 patients are shown in Table 1 . We used bilateral ITA for patients who needed revascularization of both the LAD and left circumflex artery territories. The right ITA was used as an in situ graft in 547 patients $(77.6 \%)$ and as a free graft in 158 patients $(22.4 \%)$. Our grafting strategy of right ITA is described in Table 2. When the right ITA was used as an inflow of other grafts (radial artery or saphenous vein graft), an end-to-end anastomosis was performed between grafts. We applied multiple sequential grafting with the free right ITA in patients with a limited number of grafts. When we anastomosed the free right ITA to the ascending aorta, we routinely used intraoperative epiaortic echocardiography to detect a disease-free area of the aorta. When we anastomosed the free right ITA proximally to another graft (left ITA, radial artery, or saphenous vein graft), we created a Y-composite graft.

\section{Operation}

The operative technique used for off-pump coronary artery bypass grafting has been described previously. ${ }^{6}$ All arterial grafts were harvested in a skeletonized fashion with an ultrasonic scalpel (Harmonic Scalpel; Ethicon Endosurgery, Cincinnati, Ohio). We bypassed all significantly diseased coronary vessels (at least 50\% diameter reduction) larger than $1 \mathrm{~mm}$ in diameter. We performed long segmental reconstruction when the LAD was diffusely diseased and its branches, such as septal and diagonal arteries, 


\section{Abbreviations and Acronyms \\ ITA $=$ internal thoracic artery \\ $\mathrm{LAD}=$ left anterior descending coronary artery}

were affected by severe atheromatous plaques. An arteriotomy was extended proximally and distally to the intact segment of the LAD. Additionally, we performed endarterectomy when the atheromatous plaque was circumferential or too hard to pass a needle. The left ITA was anastomosed to the LAD in a long on-lay patch fashion with 7-0 and 8-0 polypropylene running sutures. The detailed indication, technique, and outcomes of long segmental reconstruction of the LAD have been described previously. ${ }^{7}$ Although the sequential grafting to a proximal and a distal LAD could achieve the same objective, we prefer this method and have had excellent outcomes. $^{7}$

\section{Angiography}

Early postoperative angiography was performed in 579 patients $(82.1 \%)$ who gave us informed consent. Median time of early postoperative angiography was 10 days after surgery (range 1-20 days). If a patient had symptoms during follow-up, diagnostic angiography was performed at that time. For patients who did not have symptoms within 1 year after surgery, follow-up angiography was performed at 1 year. The follow-up postoperative angiography was performed for 336 patients $(47.7 \%)$ at a median of 12.2 months after surgery (range 2-21 months). Of these patients, 312 patients $(44.3 \%)$ underwent both early and 1-year angiographic studies.

We compared the preoperative, intraoperative, postoperative, and angiographic variables between patients with in situ right ITA grafts and those with free right ITA grafts. All data were collected prospectively and reviewed retrospectively. The institutional review board approved this retrospective study and waived the need for written consent.
Nonelective operations included both emergency and urgent cases according to the definition of the Society of Thoracic Surgeons database. Operative death was defined as death occurring within 30 days after surgery. Low-output syndrome was defined as the postoperative need for any dose of adrenaline or more than $5 \mu \mathrm{g} \mathrm{kg}^{-1} \mathrm{~min}^{-1}$ of dopamine or dobutamine. Perioperative myocardial infarction was defined as a positive result for new Q waves in an electrocardiogram or a peak creatine kinase MB level of greater than $10 \%$ of total creatine kinase. Respiratory failure was defined as requirement for prolonged ventilation ( $>48$ hours) or presence of pneumonia. A postoperative cerebrovascular accident was defined as a new stroke or intracranial bleeding and was confirmed by computed tomography. In patients with preoperative stroke, postoperative stroke was defined as a worsening of the neurologic deficit with new radiologic findings.

Patent graft was defined as a graft without occlusion, significant stenosis $(>90 \%)$, or string sign. String sign was defined as luminal narrowing throughout the entire conduit, including stenosis of $90 \%$ or greater. Grafts with competitive flow or reverse flow were considered patent unless they had occlusion, significant stenosis, or string sign. Competitive flow and reverse flow were defined according to the classification by Nakajima and colleagues. ${ }^{8}$ Competitive flow was defined as a situation in which the target vessel was barely opacified from the ITA graft injection and the bypass graft was filled by retrograde flow from the native coronary injection. Reverse flow was defined as a situation in which the distal anastomotic site was not opacified from the ITA graft injection at all but was filled clearly by retrograde flow from the native coronary injection.

Early and 1-year patency rates were calculated by dividing the number of patent grafts by the total number of grafts. If patients with early nonpatent grafts underwent 1-year angiography, those nonpatent grafts were also counted as 1-year nonpatent grafts.

\section{Statistical Analysis}

All statistical analyses were performed with StatView 5.0 software (SAS Institute Inc, Cary, NC). Continuous variables are reported as the mean \pm $\mathrm{SD}$ if normally distributed. Otherwise, they are reported as median.

TABLE 1. Preoperative characteristics of patients with right internal thoracic artery as in situ or free graft

\begin{tabular}{|c|c|c|c|c|}
\hline & All $(n=705)$ & In situ $(n=547)$ & Free $(\mathbf{n}=158)$ & $P$ value \\
\hline Age $(y$, mean $\pm S D)$ & $67.9 \pm 9.4$ & $68.2 \pm 9.2$ & $66.7 \pm 10.0$ & .0837 \\
\hline Sex (no. female) & $125(17.7 \%)$ & $90(16.5 \%)$ & $35(22.2 \%)$ & .1250 \\
\hline Body surface area $\left(\mathrm{m}^{2}\right.$, mean $\left.\pm \mathrm{SD}\right)$ & $1.7 \pm 0.2$ & $1.7 \pm 0.2$ & $1.6 \pm 0.2$ & .0119 \\
\hline Unstable angina (no.) & $225(31.9 \%)$ & $177(32.4 \%)$ & $48(30.4 \%)$ & .7090 \\
\hline Canadian Cardiovascular Society class (mean \pm SD) & $2.2 \pm 0.9$ & $2.3 \pm 0.9$ & $2.2 \pm 0.8$ & .5474 \\
\hline Ejection fraction $(\%$, mean $\pm \mathrm{SD})$ & $55.7 \pm 12.1$ & $55.8 \pm 11.9$ & $55.7 \pm 12.3$ & .9380 \\
\hline Diseased vessels (mean $\pm \mathrm{SD}$ ) & $2.8 \pm 0.4$ & $2.8 \pm 0.4$ & $2.9 \pm 0.3$ & .0118 \\
\hline Left main disease (no.) & $240(34.0 \%)$ & $190(34.7 \%)$ & $50(31.6 \%)$ & .5309 \\
\hline Creatinine $(\mathrm{mg} / \mathrm{dL}$, mean $\pm \mathrm{SD})$ & $1.2 \pm 1.4$ & $1.1 \pm 1.2$ & $1.4 \pm 1.9$ & .0257 \\
\hline Congestive heart failure (no.) & $95(13.5 \%)$ & $65(11.9 \%)$ & $30(19.0 \%)$ & .0299 \\
\hline Previous myocardial infarction (no.) & $344(48.8 \%)$ & $263(48.1 \%)$ & $81(51.3 \%)$ & .5385 \\
\hline Hypertension (no.) & $469(66.5 \%)$ & $365(66.7 \%)$ & $104(65.8 \%)$ & .9071 \\
\hline Diabetes mellitus (no.) & $341(48.4 \%)$ & $250(45.7 \%)$ & $91(57.6 \%)$ & .0109 \\
\hline Insulin (no.) & $79(11.2 \%)$ & $54(9.9 \%)$ & $25(15.8 \%)$ & .0517 \\
\hline Hyperlipidemia (no.) & $433(61.4 \%)$ & $337(61.6 \%)$ & $96(60.8 \%)$ & .9199 \\
\hline Smoking (no.) & $427(60.6 \%)$ & $327(59.8 \%)$ & $100(63.3 \%)$ & .4820 \\
\hline Previous stroke (no.) & $88(12.5 \%)$ & $64(11.7 \%)$ & $24(15.2 \%)$ & .3018 \\
\hline Peripheral vascular disease (no.) & $65(9.2 \%)$ & $45(8.2 \%)$ & $20(12.7 \%)$ & .1235 \\
\hline Chronic obstructive pulmonary disease (no.) & $28(4.0 \%)$ & $18(3.3 \%)$ & $10(6.3 \%)$ & .1358 \\
\hline Nonelective (no.) & $88(12.5 \%)$ & $81(14.8 \%)$ & $7(4.4 \%)$ & .0003 \\
\hline Previous percutaneous coronary intervention (no.) & $200(28.4 \%)$ & $152(27.8 \%)$ & $48(30.4 \%)$ & .5916 \\
\hline Reoperation (no.) & $9(1.3 \%)$ & $5(0.9 \%)$ & $4(2.5 \%)$ & .1195 \\
\hline
\end{tabular}


TABLE 2. Strategy for using either in situ or free right internal thoracic artery graft

\begin{tabular}{llr}
\hline \multicolumn{1}{c}{ Target } & \multicolumn{1}{c}{ Reasons } & No. \\
\hline In situ & & 547 \\
Left anterior descending artery & Unstable left main or bifurcation disease & 124 \\
Diagonal branch & Larger than other lateral vessels; inflow & 262 \\
& of radial artery graft as Y graft & 128 \\
Circumflex artery & Single major lateral vessel & 33 \\
Inflow for another graft & Diseased aorta & 158 \\
Free & & 26 \\
Diagonal branch & Multiple grafting & 132 \\
Circumflex artery & Multiple grafting & \\
\hline
\end{tabular}

Continuous variables were compared with the Student $t$ test, whereas discrete variables were compared with the $\chi^{2}$ test or Fisher exact test.

\section{RESULTS \\ Clinical Outcomes}

Preoperative characteristics of both groups are shown in Table 1. Mean body surface area was significantly larger in the in situ right ITA group than in the free right ITA group $(P=.0119)$. The mean number of diseased vessels was significantly larger in the free right ITA group than in the in situ right ITA group $(P=.0118)$. Preoperative creatinine levels were significantly higher in the free right ITA group than in the in situ right ITA group $(P=.0299)$. The free right ITA group contained a significantly larger number of patients with histories of congestive heart failure and diabetes mellitus than did the in situ right ITA group $(P=.0299$ and $P=.0109$, respectively). More patients in the in situ right ITA group underwent emergency or urgent operations than in the free right ITA group $(P=.0003)$.

Operative and postoperative variables are listed in Table 3. There was no significant difference in the mean number of distal anastomoses per patient between the groups $(P=$ .9290). The number of distal anastomoses of the right ITA, however, was higher in the free ITA group than in the in situ ITA group $(P<.0001)$.

Long segmental reconstruction of the LAD was carried out with the left ITA in 288 patients $(40.9 \%)$. The operative time in the free right ITA group was significantly longer than that in the in situ right ITA group $(P=.0007)$. The operative mortality was not significantly different between the groups $(P=0.6569)$. The incidence of postoperative complications was also not significantly different between the groups.

During the follow-up period, among the 705 patients there were 10 patients with recurrent angina, 12 with congestive heart failure, and 1 with stroke.

\section{Angiographic Outcomes}

The follow-up angiographic studies included patients without symptoms $(\mathrm{n}=326)$ and those with symptoms $(\mathrm{n}=10)$. Among the 10 patients with symptoms, percutaneous coronary intervention was performed in 5 cases. Of these
5 patients, 2 patients needed percutaneous coronary intervention for new coronary lesions. The other 3 patients needed percutaneous coronary intervention for stenosis of the gastroepiploic artery graft. Five patients who did not undergo percutaneous coronary intervention had stenosis of small native coronary arteries that were not an indication for intervention. None of these 10 patients were found to have a lesion related to the right ITA graft.

The overall patency rates of the right ITA were $98.8 \%$ at early angiography and $94.3 \%$ at 1 -year angiography. The patency rates of the left ITA were $99.1 \%$ in the early study and $97.0 \%$ in the 1-year study. There were no significant differences in the early $(P=.7732)$ and 1 -year $(P=.1288)$ patency rates between the left and right ITAs. Patency rates of various configurations of the right ITA at both early and 1-year angiographic studies are listed in Table 4.

In early examinations, there was no significant difference in the patency rate between in situ and free right ITAs ( $p>$ .9999). In the in situ right ITA group, the patency rate of the right ITA graft when used as an inflow to other grafts was significantly lower than when used as a direct graft to coronary arteries $(P=.0149)$. In the free right ITA group, the site of proximal anastomoses (composite or aorta) did not affect the patency rate $(P>$.9999). In 1-year examinations, there was also no significant difference in the patency rate between in situ and free right ITAs $(P=.1792)$. In the in situ right ITA group, the patency rate of the right ITA anastomosed to the anterior territory was superior to that of other grafting methods $(P<.0001)$. In the free group, there was no significant difference in the patency rate between sites of proximal anastomoses $(P>$.9999).

When we compared the patency rates between the anterior and posterior routes in patients with in situ right ITA, there was no difference in early patency rate between these configurations $(P=.2735)$. The 1 -year patency rate of the anterior route, however, was superior to that of the posterior route $(P=.0042)$.

Nonpatent right ITA grafts at any time are listed in Table 5. Among 21 nonpatent grafts, 16 grafts $(76.1 \%)$ were anastomosed to the coronary artery with low stenosis rate $(50 \%-75 \%)$. 
TABLE 3. Operative and postoperative data of patients with right internal thoracic artery as in situ or free graft

\begin{tabular}{|c|c|c|c|c|}
\hline & All $(n=705)$ & In situ $(n=547)$ & Free $(\mathbf{n}=158)$ & $P$ value \\
\hline Anastomoses per patient (mean $\pm \mathrm{SD})$ & $4.2 \pm 1.2$ & $4.2 \pm 1.2$ & $4.2 \pm 1.1$ & .9290 \\
\hline Anastomoses of right internal thoracic artery per patient $($ mean $\pm \mathrm{SD})$ & $1.1 \pm 0.5$ & $1.0 \pm 0.3$ & $1.7 \pm 0.7$ & $<.0001$ \\
\hline Grafts per patient $($ mean $\pm S D)$ & & $3.3 \pm 0.6$ & $3.1 \pm 0.5$ & $<.0001$ \\
\hline Long segment reconstruction of left anterior descending artery (no.) & $288(40.9 \%)$ & $218(39.9 \%)$ & $70(44.3 \%)$ & .3625 \\
\hline Operative time (min, mean $\pm \mathrm{SD}$ ) & $282.3 \pm 59.1$ & $278.3 \pm 57.9$ & $296.3 \pm 61.2$ & .0007 \\
\hline Transfusion (no.) & $257(36.5 \%)$ & $192(35.1 \%)$ & $65(41.1 \%)$ & .1952 \\
\hline Intubation $(\mathrm{h}$, mean $\pm \mathrm{SD})$ & $10.1 \pm 16.2$ & $10.4 \pm 17.3$ & $9.0 \pm 11.1$ & .3359 \\
\hline Intensive care unit stay $(\mathrm{d}$, mean $\pm \mathrm{SD})$ & $2.0 \pm 8.2$ & $2.1 \pm 9.2$ & $1.7 \pm 1.6$ & .5414 \\
\hline Operative death (within $30 \mathrm{~d}$, no.) & $7(1.0 \%)$ & $5(0.9 \%)$ & $2(1.3 \%)$ & 6569 \\
\hline Reexploration for bleeding (no.) & $6(0.9 \%)$ & $4(0.7 \%)$ & $2(1.3 \%)$ & .6208 \\
\hline Low output syndrome (no.) & $12(1.7 \%)$ & $10(1.8 \%)$ & $2(1.3 \%)$ & $>.9999$ \\
\hline Perioperative myocardial infarction (no.) & $12(1.7 \%)$ & $9(1.6 \%)$ & $3(1.9 \%)$ & .7366 \\
\hline Severe ventricular arrhythmia (no.) & $5(0.7 \%)$ & $2(0.4 \%)$ & $3(1.9 \%)$ & .0774 \\
\hline Atrial fibrillation (no.) & $186(26.4 \%)$ & $147(26.9 \%)$ & $39(24.7 \%)$ & .6542 \\
\hline Hemodialysis required (no.) & $14(2.0 \%)$ & $10(1.8 \%)$ & $4(2.5 \%)$ & .5282 \\
\hline Stroke (no.) & $8(1.1 \%)$ & $6(1.1 \%)$ & $2(1.3 \%)$ & $>.9999$ \\
\hline Mediastinitis (no.) & $12(1.7 \%)$ & $7(1.3 \%)$ & $5(3.2 \%)$ & .1534 \\
\hline
\end{tabular}

We also analyzed the subgroup of 312 patients (44.3\%) who underwent both early and 1-year angiographic studies. In this subgroup of patients, there were no significant differences in the patency rate at early $(P>.9999)$ and 1 -year $(P=.0711)$ angiography between in situ and free right ITA groups. Among patients with in situ right ITA grafts $(\mathrm{n}=$ 257), 4 patients had nonpatent right ITA in the early study and 10 patients had nonpatent right ITA in the 1-year study. Six patients had newly developed nonpatency of right ITA graft at the 1-year study. Four of these 6 patients had a low stenosis rate $(50 \%-75 \%)$ in the target coronary artery.

On the other hand, among patients with a free right ITA $(\mathrm{n}=55)$, there was 1 patient whose right ITA was not patent in the early study and 6 patients whose right ITAs were not patent in the 1-year study. Five patients had newly developed nonpatent free right ITA grafts at the 1-year study. These 5 patients had a low stenosis rate $(50 \%-75 \%)$ of the target coronary artery.

\section{DISCUSSION}

The right ITA is frequently used as a second or third arterial graft, as well as the radial artery or gastroepiploic artery. ${ }^{9}$

TABLE 4. Cumulative angiographic patency rates of in situ and free right internal thoracic artery grafts

\begin{tabular}{lcc}
\hline & Early $(\mathbf{n}=\mathbf{5 7 9})$ & $\mathbf{1} \mathbf{y}(\mathbf{n}=\mathbf{3 3 6})$ \\
\hline Total & $98.8 \%(572 / 579)$ & $94.3 \%(317 / 336)$ \\
In situ & $98.6 \%(438 / 444)$ & $95.3 \%(264 / 277)$ \\
$\quad$ Anterior & $99.4 \%(307 / 309)$ & $98.5 \%(197 / 200)$ \\
Lateral & $98.1 \%(105 / 107)$ & $89.3 \%(50 / 56)$ \\
$\quad$ Inflow & $92.9 \%(26 / 28)$ & $81.0 \%(17 / 21)$ \\
Free & $99.3 \%(134 / 135)$ & $89.8 \%(53 / 59)$ \\
$\quad$ Composite graft & $99.1 \%(105 / 106)$ & $89.8 \%(44 / 49)$ \\
$\quad$ Aorta & $100 \%(29 / 29)$ & $90 \%(9 / 10)$ \\
\hline
\end{tabular}

All figures represent percentages of patent grafts, with numbers of patent grafts and total grafts given in parentheses.
Because the right ITA is anatomically the same as the left ITA, a longer patency duration would be expected than with other arterial grafts. Because the length of the right ITA when it is used as an in situ graft is sometimes not sufficient for revascularization for lateral vessels, however, several configurations have been proposed,${ }^{10}$ such as an in situ graft to the LAD and a free graft with proximal anastomoses to the aorta or an in situ left ITA. Although there have been many reports describing the feasibility and efficacy of each technique, little has been reported about angiographic patency rates comparing several configurations simultaneously. This study demonstrated that clinical and angiographic outcomes were not significantly different between in situ and free right ITA grafts at early and 1-year followup. Additionally, in situ right ITA grafting to the LAD system had a superior patency rate to other types of right ITA grafting at early and 1-year angiography.

When the right ITA is used as an in situ graft, it can be useful for revascularization of anterior or lateral vessel for single anastomosis. When the in situ right ITA is anastomosed to the LAD or diagonal branch, it is directed anterior to the aorta. ${ }^{11}$ In such cases, the right ITA should be wrapped in thymic tissue and covered with mediastinal fat to prevent injury at reopening. ${ }^{12} \mathrm{We}$ used an in situ right ITA for revascularization of the anterior territory in $70.7 \%$ of patients. An in situ right ITA has sufficient length to reach anterior vessels in almost all patients. It is useful for unstable left main and bifurcation disease when combined with the use of an in situ left ITA for lateral vessels. When the right ITA is anastomosed to the circumflex artery territory, it is passed through the transverse sinus. ${ }^{13}$ In such cases, care should be taken not to twist the graft. We used an in situ right ITA for lateral territory in $23.2 \%$ of patients. It is useful for revascularization of single major lateral vessel when it is long enough. In this study, the patency rate at 1-year 
TABLE 5. Occluded right internal thoracic artery grafts

\begin{tabular}{clcc}
\hline \multicolumn{1}{c}{ Inflow } & Target vessel & $\begin{array}{c}\text { Degree of native } \\
\text { coronary stenosis }\end{array}$ & $\begin{array}{c}\text { Occluded } \\
\text { grafts }\end{array}$ \\
\hline In situ & & & \\
Right ITA & Left anterior & $50 \%$ & 1 \\
& descending artery & & \\
& Diagonal branch & $50 \%$ & 1 \\
& & $90 \%$ & 2 \\
& Circumflex artery & $50 \%$ & 2 \\
Free & & $75 \%$ & 3 \\
Left ITA & Diagonal branch & $90 \%$ & 2 \\
\multirow{3}{*}{ Radial artery } & Circumflex artery & $75 \%$ & 4 \\
& Diagonal branch & $75 \%$ & 1 \\
Aorta & Circumflex artery & $50 \%$ & 2 \\
ITA, Internal thoracic artery. & $50 \%$ & 1 \\
& Circumflex artery & & 1 \\
\hline
\end{tabular}

angiography was superior when an in situ right ITA was used for anterior territory relative to when it was used for lateral territory.

A free right ITA graft is useful for revascularization of lateral or posterior vessels for single or multiple sequential anastomoses. It can reach the posterior descending artery with composite grafting when its proximal anastomosis is carried out on the left ITA. ${ }^{14}$ Multiple sequential grafting to lateral vessels with the free right ITA can reduce the total number of grafts. In this study, the mean number of grafts was significantly less in the free right ITA group than in the situ right ITA group $(P<.0001)$. Furthermore, the mean number of distal anastomoses of the free right ITA was significantly higher than that of the in situ right ITA $(P<.0001)$. The proximal anastomosis site of the free right ITA (other grafts or aorta) did not affect the patency rate at both of early and 1-year angiographic studies. Calafiore and colleagues ${ }^{15}$ reported that the patency rate of the free right ITA proximally anastomosed to the aorta was inferior to that anastomosed to the left ITA. They suggested that the reason for this poor graft patency rate was because of a mismatch between the aorta and the conduit wall and a difference in the flow pattern. We did not observe an inferior patency rate of the free right ITA anastomosed to the aorta relative to that anastomosed to other grafts. We speculate that the routine use of intraoperative epiaortic echocardiography to detect a disease-free area of the aorta for proximal anastomosis may minimize the mismatch of the wall discrepancy.

There have been a few reports comparing the patency rates between the in situ right ITA and the free right ITA. ${ }^{16,17} \mathrm{Re}$ cently, Glineur and associates ${ }^{18}$ demonstrated that patency rates were not different between an in situ group and a Ygrafting group at 6-month postoperative angiography in a prospective randomized trial. Our 1-year follow-up study supports their findings. In this study, both early and 1-year angiographic studies were performed in 312 patients. Among those patients, 11 patients were newly found to have nonpatent right ITA grafts at 1-year angiography. The target coronary arteries had a low stenosis rate in 9 of these 11 patients. Competitive or reverse flow related to a low stenosis rate could be the potential cause of 1-year new nonpatency. It has been suggested that arterial grafts tend to fail when they are used for revascularization of target vessels with low-grade stenosis. ${ }^{8}$ This tendency was observed in both the in situ and free right ITA grafts in our study.

A skeletonized ITA provides a longer length and better flexibility than a pedicled ITA. Skeletonization ensures that the right ITA reaches the posterolateral vessels through the transverse sinus as an in situ graft. Furthermore, multiple sequential grafting can be easily performed with a skeletonized free right ITA. The blood flow of a skeletonized ITA is reported to be greater than that of a pedicled ITA. ${ }^{19} \mathrm{With}$ the skeletonization technique, the use of bilateral ITAs might no longer be a risk factor for mediastinitis, because the collateral blood supply to the sternum can be preserved. ${ }^{20,21}$

In situ ITA grafts are sometimes at risk for injury in reoperations. Recently, Roselli and colleagues ${ }^{22}$ reported an occurrence of ITA injury of $3 \%$ at reoperative cardiac surgery. They commented that the best way to prevent injury to a patent ITA graft is to position it properly at the original operation. Preventive strategies are not always effective, however, and intraoperative adverse events are difficult to eliminate. On the other hand, Endo and coworkers ${ }^{12}$ reported that the right ITA was surrounded by loose connective tissue at reoperation and the patent ITA did not increase the risk of reoperation in their study. Our own study showed that the best patency of the right ITA could be obtained with in situ grafting to the LAD. Other configurations, however, such as in situ grafting to the lateral wall through the transverse sinus and free grafting to the lateral vessel with Y-composite graft, had only slightly inferior patency. These configurations may be much safer at reoperation than in situ right ITA graft to the LAD. The actual graft strategy should be made after considering the risk of injury at potential reoperations as well as graft patency outcomes.

This clinical study has the several limitations. It was a retrospective observational study and was not randomized. Also, we could not follow up all patients with right ITA grafts. Our findings may not be applicable in such groups as elderly patients and patients with renal insufficiency, who did not have undergo follow-up angiography.

In conclusion, patency rates of in situ and free right ITAs were identical at early and 1-year angiographic studies. In situ grafting to the LAD had the best patency among various configurations of right ITA graft; however, other configurations had also excellent patency. Grafting strategy of right ITA should be determined on the basis of conduit availability, target location, and other clinical factors. 


\section{References}

1. Loop FD, Lytle BW, Cosgrove DM, Stewart RW, Goormastic M, Williams GW, et al. Influence of the internal-mammary-artery graft on 10-year survival and other cardiac events. N Engl J Med. 1986;314:1-6.

2. Taggart DP, D'Amico R, Altman DG. Effect of arterial revascularization on survival: a systematic review of studies comparing bilateral and single internal mammary arteries. Lancet. 2001;358:870-5.

3. Cameron A, Davis KB, Green G, Schaff HV. Coronary bypass surgery with internal-thoracic-artery grafts-effects on survival over a 15 -year period. $N$ Engl $J$ Med. 1996;334:216-9.

4. Buxton BF, Ruengsakulrach P, Fuller J, Rosalion A, Reid CM, Tatoulis J. The right internal thoracic artery graft-benefits of grafting the left coronary system and native vessels with a high grade stenosis. Eur J Cardiothorac. Surg. 2000;18:255-61.

5. Ascione R, Underwood MJ, Lloyd CT, Jeremy JY, Bryan AJ, Angelini GD. Clinical and angiographic outcome of different surgical strategies of bilateral internal mammary artery grafting. Ann Thorac Surg. 2001;72:959-65.

6. Fukui T, Takanashi S, Hosoda Y, Suehiro S. Early and midterm results of offpump coronary artery bypass grafting. Ann Thorac Surg. 2007;83:115-9.

7. Fukui T, Takanashi S, Hosoda Y. Long segmental reconstruction of diffusely diseased left anterior descending coronary artery with left internal thoracic artery with or without endarterectomy. Ann Thorac Surg. 2005;80:2098-105.

8. Nakajima H, Kobayashi J, Tagusari O, Niwaya K, Funatsu T, Kawamura A, et al. Angiographic flow grading and graft arrangement of arterial conduits. $J$ Thorac Cardiovasc Surg. 2006;132:1023-9.

9. Barner HB. Arterial grafting: techniques and conduits. Ann Thorac Surg. 1998; 66(5 Suppl):S25-8; discussion S25-8

10. Pevni D, Uretzky G, Mohr A, Braunstein R, Kramer A, Paz Y, et al. Routine use of bilateral skeletonized internal thoracic artery grafting: long-term results. Circulation. 2008;118:705-12.

11. Chow MS, Sim E, Orszulak TA, Schaff HV. Patency of internal thoracic artery grafts: comparison of right versus left and importance of vessel grafted. Circulation. 1994;90(5 Pt 2):II129-32.

12. Endo M, Nishida H, Tomizawa Y, Kasanuki H. Benefit of bilateral over single internal mammary artery grafts for multiple coronary artery bypass grafting. Circulation. 2001;104:2164-70.
13. Puig LB, França Neto L, Rati M, Ramires JA, da Luz PL, Pileggi F, et al. A technique of anastomosis of the right internal mammary artery to the circumflex artery and its branches. Ann Thorac Surg. 1984;38:533-4.

14. Navia D, Vrancic M, Vaccarino G, Piccinini F, Raich H, Florit S, et al. Total arterial off-pump coronary revascularization using bilateral internal thoracic arteries in triple-vessel disease: surgical technique and clinical outcomes. Ann Thorac Surg. 2008;86:524-30.

15. Calafiore AM, Di Giammarco G, Luciani N, Maddestra N, Di Nardo E, Angelini R. Composite arterial conduits for a wider arterial myocardial revascularization. Ann Thorac Surg. 1994;58:185-90.

16. Calafiore AM, Contini M, Vitolla G, Di Mauro M, Mazzei V, Teodori G, et al. Bilateral internal thoracic artery grafting: long-term clinical and angiographic results of in situ versus Y grafts. J Thorac Cardiovasc Surg. 2000; 120:990-6.

17. Lev-Ran O, Pevni D, Matsa M, Paz Y, Kramer A, Mohr R. Arterial myocardial revascularization with in situ crossover right internal thoracic artery to left anterio descending artery. Ann Thorac Surg. 2001;72:798-803.

18. Glineur D, Hanet C, Poncelet A, D'hoore W, Funken JC, Rubay J, et al Comparison of bilateral internal thoracic artery revascularization using in situ or Y graft configurations: a prospective randomized clinical, functional, and angiographic midterm evaluation. Circulation. 2008;118(14 Suppl): S216-21.

19. Gurevitch J, Kramer A, Locker C, Shapira I, Paz Y, Matsa M, et al. Technical aspects of double-skeletonized internal mammary artery grafting. Ann Thorac Surg. 2000;69:841-6.

20. Parish MA, Asai T, Grossi EA, Esposito R, Galloway AC, Colvin SB, et al. The effects of different techniques of internal mammary artery harvesting on sternal blood flow. J Thorac Cardiovasc Surg. 1992;104:1303-7.

21. Higami T, Maruo A, Yamashita T, Shida T, Ogawa K. Histologic and physiologic evaluation of skeletonized internal thoracic artery harvesting with an ultrasonic scalpel. J Thorac Cardiovasc Surg. 2000;120:1142-7.

22. Roselli EE, Pettersson GB, Blackstone EH, Brizzio ME, Houghtaling PL, Hauck R, et al. Adverse events during reoperative cardiac surgery: frequency, characterization, and rescue. J Thorac Cardiovasc Surg. 2008;135:316-23. 323.e1-6. 